\title{
LA NARRATIVA DE ARMANDO LÓPEZ SALINAS: REALISMO CRÍTICO \\ CONTRA CENSURA
}

\section{LUCÍA MONTEJO GURRUCHAGA ${ }^{1}$}

Facultad de Filología. Universidad Nacional de Educación a Distancia. UNED

\section{Resumen}

Las obras de Armando López Salinas tuvieron serias dificultades para poder editarse en España; la censura franquista le denegó el permiso para algunas y le mutiló sustancialmente otras. Este artículo estudia, a la luz de los expedientes de censura de todas ellas, las dolorosas circunstancias que nuestro autor tuvo que padecer, el enfrentamiento sistemático con ese mecanismo de control y los resultados de esa lucha desigual, que no fueron otros que el silencio y el olvido.

Palabras clave: Armando López Salinas, realismo crítico, censura, inéditos.

\begin{abstract}
Armando Lopez Salinas's works had serious difficulties to get published in Spain; censorship under Franco's regime denied permission for some of them and others were severely mutilated. This paper studies, in the light of the processes of censorship of all his works, the painful circumstances the author had to undergo, the systematic clash with that controlling mechanism and the results of that uneven fight, which ended in nothing different from silence and oblivion.
\end{abstract}

Key words: Armando López Salinas, critical realism, censorship, unpublished works

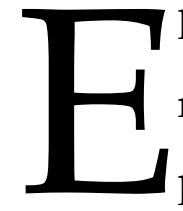

1 acceso a las obras de Armando López Salinas sigue aún hoy presentando muchas dificultades. Algunas tuvieron que ser publicadas con abundantes páginas mutiladas y con retraso respecto al tiempo de escritura. Pero, además, y lo que es más grave, la férrea acción censoria le obligó no sólo a dar a

\footnotetext{
${ }^{1}$ Profesora de la UNED. Correo-e: lmontejo@flog.uned.es. Recibido: 02-01-2009; segunda versión: 3004-2009.
} 
conocer varias fuera de España, lo que impidió que llegaran al público y que la crítica las valorara y analizara, sino a guardar, además, para tiempos más propicios materiales inéditos que hoy siguen en hibernación.

La censura franquista le empuja a publicar en 1962, en Francia, Año tras año, su segunda novela, y en 1965, en Suecia, Estampas madrileñas, un libro de relatos del que hoy es imposible encontrar un ejemplar. En 1964, el volumen de cuentos Crónica de un viaje y otros relatos, tampoco podrá publicarse. Sus libros de viajes, de autoría compartida, no corrieron mejor suerte; Por el río abajo, escrito con Alfonso Grosso, se publicará en París, y Viaje al país gallego, que firma con Javier Alfaya, después de sufrir serios encontronazos con la censura será publicado, con múltiples tachaduras, en 1967. Tras estos avatares guardará un tiempo de silencio que le llevará al abandono de la literatura para dedicarse a la política a partir de la llegada de la democracia.

En este artículo me propongo dar a la luz las rocambolescas circunstancias que hicieron que Armando López Salinas fuera un escritor ignorado y sus obras, de calidad literaria probada, no tuvieran el eco que merecían. Las reediciones que se han preparado después de la transición política no han podido reparar el daño producido.

He consultado los expedientes de censura de todas sus obras, que están en el Archivo General de la Administración en Alcalá de Henares y su estudio me ha desvelado el acoso que el autor padeció a lo largo de toda su trayectoria literaria; sus obras, tachadas de comunistas y peligrosas para los lectores españoles, fueron sistemáticamente cercenadas. Mostraré algunos de los párrafos mutilados en los manuscritos para que el lector pueda darse cuenta de los criterios por los que se regían los censores.

López Salinas fue siempre consciente del peligro que sus obras corrían tras su toma de postura política, su adscripción a una ideología determinada -perseguida siempre con encono por el Régimen franquista- y su empeño en mostrar la realidad más injusta, una mirada del lado de los vencidos. Hizo siempre declaraciones en este 
sentido; su propósito era "hacer objeto de crítica la realidad española" (Olmos García, 1963: 223). En declaraciones posteriores irá más lejos y cuando el ataque a la novela social -sobre todo a partir de 1962- era ya furibundo por gran parte de la crítica y de muchos escritores que la habían practicado, el seguirá defendiendo el uso de la literatura para hacer política, sin tapujos ni medias verdades, con estas palabras:

yo creo que el problema de la política en literatura, el problema de lo social en literatura entendiendo por social la expresión testimonial de formas de vida- no es precisamente un desdoro para la literatura. Si después del 39 hubo un intento de literatura heroica y combatiente, imperial, que se rompe en los años 44-45 y fue válido entonces el ingrediente ideológico y político, no debemos preocuparnos de que se nos acuse de que la base de nuestra expresión es política (Núñez, 1966: 4).

El compromiso político de López Salinas es ya visible en sus primeros relatos de mediados de los cincuenta, compromiso que se convertirá en desafío con su participación en los foros que combatían por la libertad en España².

Los escritores de la generación de los 50, de forma especial el grupo de los madrileños -muchos de los cuales habían venido de provincias-, entre los que se incluían Juan García Hortelano, José Manuel Caballero Bonald, Armando López Salinas, Daniel Sueiro, Jesús López Pacheco, Antonio Ferres, Carmen Martín Gaite y Alfonso Grosso, eran muy activos en la cultura y en la política y casi todos se hicieron miembros o aliados del Partido Comunista ${ }^{3}$.

\footnotetext{
2 Antonio Ferres recuerda su encuentro con A. López Salinas en el laboratorio donde ambos trabajaban. En los todavía oscuros años de finales de los cincuenta -dice Ferres-, los vínculos que entre algunos amigos se iban tejiendo en torno a la vocación literaria y al ansia de participar en la recuperación de la libertad, fueron decisivos para el desarrollo de la corriente artística que vino en llamarse realismo crítico o realismo social (2002: 79).

${ }^{3}$ Shirley Mangini dice que casi todos los escritores del grupo han señalado el año 1956 como el del inicio de su conciencia política y su consiguiente dedicación a la literatura comprometida (1987: 100).
} 
Pero mostrar y defender en la ficción esta ideología aunque fuera veladamente, era difícil en aquellas décadas de férrea censura y todos ellos tendrán que vérselas con este aparato represor 4 .

La primera novela de López Salinas, La mina, fue finalista en el premio Nadal de 19595. La crítica coincide entonces al señalar que se trata de uno de los relatos obreristas más significativos de la época. Uno de los miembros de jurado dijo que era la gran revelación de la convocatoria por su sencillez, y la variedad y autenticidad de los personajes (Vázquez Zamora, 1960: 24). Se repiten los juicios en este sentido. "Afortunadamente, escribe Santos Fontenla, parece que hay un grupo de jóvenes novelistas decididos a escribir con franqueza y modernamente. López Salinas pertenece a él. Su realismo es eficaz" (1960: 129). Otros dicen que se revela dueño de su tema y de sus medios expresivos (Gil Novales, 1961: 141) y que describe certeramente, sabe orquestar con habilidad los elementos, y su estilo posee fuerza y categoría (Conte, 1960: 34).

La crítica posterior mantiene en términos generales estas valoraciones. Juan Ignacio Ferreras observa que López Salinas logra, a pesar del tema, individualizar la

\footnotetext{
${ }^{4}$ Después del aislamiento internacional que el franquismo sufre hasta los inicios de la década de los cincuenta, con su posterior aceptación se favorece el desarrollo del turismo y empieza una época más expansiva en lo económico. Se producen algunos cambios en el Gobierno y en el terreno cultural surge una nueva generación de escritores que hará evolucionar el panorama. Aunque la censura, bajo el mando del católico integrista Arias Salgado, será férrea y la crítica está casi reducida sistemáticamente al silencio, muchos textos se divulgarán en revistas universitarias y en editoriales progresistas y se producirán los primeros signos de protesta. Sin embargo, en las filas del Gobierno hay gran presencia del Opus Dei y esto hace que aumente el poder de la Iglesia con la consiguiente represión en la censura. Más información sobre la organización de este mecanismo de control, la eficacia y la influencia que alcanzó, la encontrará el lector interesado en los libros de Abellán (1980), Gubern (1981), Neuschäfer (1994), Sinova (1989). Muchos escritores de la generación de los 50 verán sus obras mutiladas y recurrirán a estrategias diversas para intentar salvarlas. Sobre estos temas remito a algunos de mis últimos artículos (2004, 2006, en prensa).

${ }^{5}$ Tuvo ediciones sucesivas hasta 1980. A partir de esa fecha será Orbis la que, desde 1984, seguirá editándola con regularidad.
} 
lucha de clases y evita la solución "épica" al materializarla en un apretado y bien definido grupo de protagonistas (1970: 185). Gonzalo Sobejano centra el acierto de La mina en la "veracidad convincente del relato" (1975: 415). Santos Sanz Villanueva, que coincide en su valoración con los críticos que le preceden, pone el inconveniente en "un planteamiento bastante maniqueo que es, quizás, el punto más débil de la obra" (1980: 577). La censura autorizó su publicación sin condiciones y fue inmediatamente publicada 6 .

Pero las cosas se van a torcer con su segunda novela titulada Año tras año. López Salinas acentúa en ella el carácter político de la primera y va a reflejar las condiciones de vida del proletariado madrileño desde el fin de la guerra civil en 1939, hasta la huelga de los tranvías de 1951. La novela quiere ser un documento histórico y sociológico de la inmediata posguerra. El autor aborda abiertamente temas como el miedo de la población a las denuncias, los chivatos infiltrados en todas partes, la cárcel y los interrogatorios, las depuraciones, el realquiler de la vivienda, el hambre, la alianza entre Iglesia y Estado. No hay una historia única sino una amalgama de sucesos discontinuos que pretenden ofrecer una visión amplia de la realidad. Un narrador en tercera persona presenta un mosaico de personajes -casi todos de clase obrera y vida mísera- que viven en una casa de realquilados en el Madrid de la posguerra. Matías, viudo y con un hijo -Joaquín-, se casa con María para tener a alguien que les atienda. Las continuas peleas a causa del paro y el hambre, le harán huir; Joaquín se convertirá en un obrero comprometido y junto a otros compañeros -Enrique, Augusto, González- emprenderá acciones políticas. Antonia es otro personaje relevante. Vive con su tía Aurea y su hermano Pedro en otra habitación; tras muchas penalidades conoce a Luis, un abogado que da sus

\footnotetext{
${ }^{6}$ Abellán, que ha consultado el expediente de esta novela en el Archivo General de la Administración, en Alcalá de Henares -número 654/60-, transcribe el informe del censor, que entre otras cosas señala que es una "novela social, pero sin demagogia, sin moraleja y con rigor y objetividad" (1980:186) Casi inmediatamente fue traducida al francés (La mine, traduit de l'espagnol par Bernard François, Gallimard, Paris, 1962) y a otros idiomas. Recibió alguna crítica elogiosa como la de M. Boulanger (1962: 334-335).
} 
primeros pasos, y decidirán vivir juntos. El papel de la mujer, como compañera del hombre y comprometida en la lucha, que López Salinas le asigna, representa un gran avance respecto al que se la destina en la ficción de la época.

Año tras año es una novela de esperanza en el cambio futuro, una novela política de ideología socialista que defiende la lucha de clases, una propuesta excepcional en la novela del medio siglo. Seguramente, autor y editor sabían que presentarla a censura era un suicidio.

La editorial Seix Barral, que asume su publicación, pide la autorización el 9 de junio de 19617. El permiso le será denegado quince días después y aunque solicita la revisión del expediente tan pronto como conoce el veredicto, la sentencia se mantendrá firme, lo que se le comunicará el 17 de julio ${ }^{8}$.

La novela cae en manos de un censor -el lector 11- que, tras señalar que ataca al régimen y a sus instituciones y que los pasajes censurables se refieren al contenido total de la obra, redacta el siguiente informe 9 :

\footnotetext{
7 Con el establecimiento del premio Biblioteca Breve en 1958, la actuación de Barral fue sustancial porque empezó a fomentar y asumir la edición de la novela social realista. La decisión de Carlos Barral fue motivada por sus relaciones con el Partido Comunista porque, como detenidamente explica en sus memorias, "el monopolio del partido en materia de resistencia intelectual era casi absoluto. Sólo a los comunistas les interesaban los intelectuales y aún más los resortes de difusión de la cultura insumisa" (1978: 232).

8 Se trata del expediente número 3458-61 y está en el AGA. La editorial catalana solicita el permiso para imprimir 4000 ejemplares.

${ }_{9}^{9}$ Los censores -lectores en el argot ministerial- se identificaban por un número y, por lo general, estampaban al final del informe una firma ilegible, sobre todo si era negativo. Algunos eran funcionarios del régimen franquista o personal eventual de escasa formación, pero había otros relacionados con el mundo literario -escritores o críticos afines al Régimen- o con el mundo universitario -historiadores, profesores-. Dada la relevante posición de la Iglesia católica, los lectores eclesiásticos tenían, en muchas ocasiones, la última palabra. Copio los informes tal y como aparecen en los documentos originales.
} 
La obra se desarrolla en la España de la posguerra y tiene como protagonistas a obreros "explotados" por el Régimen, perseguidos por la policía y que esperan un cambio en España". La obra es claramente FILOCOMUNISTA. Ver el párrafo final en la página 349, y entre otras cientos, las de la 46, 77, 141, 200 (este muy claro), 243, 259, 335... Además párrafos soeces que no pueden serlo más (página 56, etc.). TERMINANTEMENTE IMPUBLICABLE.

Carlos Barral, en nombre de la editorial, solicita de inmediato la revisión con una carta en la que alega en su defensa, que "la novela es altamente representativa de la literatura que escriben los jóvenes autores españoles, que no contiene afirmaciones de tipo político y que su verdadero tema es el análisis de la problemática de orden moral, psicológico y de las relaciones humanas en el ámbito del proletariado español10." El asesor político, de quien depende en este caso la revisión, no cambiará el fallo emitido. Año tras año será editada en Francia pocos meses después con los inevitables problemas de recepción y el consiguiente nulo eco de crítica. Pasó totalmente desapercibida ${ }^{11}$.

El expediente contiene el manuscrito de la obra con todos los párrafos tachados por el lápiz del censor. Casi todos son de cariz político; unos defienden el ideario socialista, otros denuncian las atrocidades cometidas por el ejército de "liberación" al final de la guerra civil, o reflejan la miseria del proletariado. Voy a extraer, como ejemplo, algunos de esos fragmentos mutilados. En boca de Enrique un obrero comprometido- pone el narrador las siguientes palabras:

10 Era frecuente que los editores pelearan ante la censura en defensa de los escritores a los que representaban. Hay muchas cartas de este carácter en los expedientes. Con frecuencia, sus alegaciones eran tenidas en cuenta y de forma especial, si representaban a editoriales de peso.

${ }^{11}$ Muchos años tendrá que esperar el autor para ver la obra publicada en su país. Ocurrirá en el año 2000 (Alcayuela, Salamanca), con una introducción de Eugenio de Nora. Ricardo Doménech llama la atención sobre cuatro obras de autores jóvenes cuyo denominador común es no haber podido ser publicadas en España. Se trata de Teatro de Alfonso Sastre (Buenos Aires, 1960), Pongo la mano sobre España de Jesús López Pacheco (Roma, 1961), La Chanca de Juan Goytisolo (París, 1962) y Año tras año de Armando López Salinas (1962: 4). El estudio más detenido sobre esta segunda obra de López Salinas lo lleva a cabo Pablo Gil Casado (1973: 348-350, 359-361). 
Cuando los hombres se den cuenta del por qué de las cosas no habrá más guerras. Los obreros no necesitamos las guerras, los capitalistas sí. Mientras haya gente como ellos no tendremos paz ni alegría. Nos quieren robar la verdad. Yo una vez oí hablar a una persona que entendía de esas cosas; dijo que nadie tenía derecho a vivir del trabajo de nadie; dijo que había que luchar por conseguirlo, que más valía morir de pie que vivir de rodillas (manuscrito: 77).

Aída López, viuda y realquilada como los demás, conversa con Matías sobre los comportamientos de los nacionales y su alianza con la Iglesia en su pueblo, y dice:

Cuando entraron los nacionales, en venganza, fusilaron más de un ciento entre hombres y mujeres. Los formaron en la Plaza del Caudillo y se los llevaron andando hasta el cementerio. Allí les hicieron cavar dos fosas mientras don Dámaso les daba la absolución. A unos les dieron a comer sopas de pan y ricino. Y se iban por las piernas abajo, con perdón. A las mujeres les cortaron el pelo al cero, pero les dejaron un mechón largo, igualito que las colas de las mulas, y les pusieron un lazo con la bandera monárquica. Se tenían que presentar en el cuartelillo, para luego ir a barrer las calles del pueblo. Por los dos lados se hicieron cosas malas (manuscrito: 141).

Luis, con la carrera de Derecho recién terminada, se propone sacar a Antonia su novia- de la mísera vida de miedo, hambre y compromiso, y piensa:

El grito de Antonia es como la voz de la España triste, la España de las cárceles y los fusilados, de los campesinos sin tierra, de los obreros sin trabajo y con hambre (manuscrito: 200).

De forma simultánea a la publicación y escritura de sus novelas, y en la misma línea de sus compañeros de generación, López Salinas ensayó también el relato breve. En 1960, el titulado "Aquel abril" le proporcionó el premio Acento para Cuentos aunque no fue publicado hasta $1963^{12}$. En 1962, la revista Triunfo recoge el

\footnotetext{
12 Este relato fue incluido en la Antología de Cuentos de hoy, Labor, Barcelona-Madrid-Buenos Aires-Río de Janeiro-México-Montevideo, 1963: 64-69. Selección realizada en el Concurso Internacional convocado por los periódicos norteamericanos New York Herald Tribune y New York Universal Features entre los cuentos premiados en diferentes países, con adición de los galardonados en Certámenes españoles celebrados en la misma época. Entre los relatos de la parte española hay algunos firmados por autores tan representativos como Miguel Delibes, Antonio Ferres, Jesús López Pacheco o Daniel Sueiro. En 1964 este cuento formará parte del manuscrito de Crónica de un viaje y otros relatos que nuestro autor remite a censura.
} 
titulado "Una historia familiar"13. En él se narra la historia de Luis, un niño de doce años al que su madre manda a un pueblo de Navarra con sus abuelos maternos cuando su padre, republicano, es encarcelado en Ocaña tras la guerra civil. El abuelo, católico integrista y defensor del más rancio tradicionalismo español, que odia al yerno, quiere hacer al nieto a su imagen y semejanza, pero este se rebela porque el ejemplo del padre es el pilar de su vida. Por esta causa, el abuelo le rechaza hasta en los momentos anteriores a su muerte, que ocurrirá de forma accidental. Es un relato de claro cariz político y personajes maniqueos que, sorprendentemente la revista pudo publicar.

La crítica no menciona que López Salinas escribiera relatos y además, no son estos los únicos. En el AGA he encontrado el expediente de Crónica de un viaje y otros relatos que contiene un número importante de inéditos ${ }^{14}$. El manuscrito pasó por distintos censores que requirieron información de los servicios policiales sobre las actividades de López Salinas. El primero, tras señalar que son relatos de tema social en los que se fustigan las desigualdades sociales, pone serios reparos en tres de ellos "Aquel Abril", "Debajo del cerezo" y "La risa"- que deben suprimirse, dice, por ser un ataque al ejército nacional y alentar el espíritu de revancha o desquite del bando rojo. Las objeciones salpican a pasajes de otros aunque admite que, si se cumplen las condiciones impuestas, el volumen puede publicarse.

Un segundo censor advierte que "el autor se encuentra entre los novelistas que se definen entre otras características por no haber hecho ni vivido la guerra, y al tomar posiciones coinciden en tomar las de enfrente" y observa que:

\footnotetext{
${ }^{13}$ Se le concederá el Gran premio “Triunfo” de narraciones 1963.

14 Se le asignó el número de expediente 147-64. La solicitud para la edición, de fecha 7 de enero de 1964, lleva la firma Seix Barral y contiene, además del manuscrito, documentación variada reservada de organismos oficiales competentes, dada ya entonces la significación política de su autor. Manuel L. Abellán señala que este libro de relatos quedó inédito tras la supresión de treinta y tres páginas, pero no muestra el expediente ni analiza ninguna de las páginas censuradas (1980: 81,103).
} 
Hay dos cuentos rechazables por entero, "Aquel Abril", un relato muy sentimental y muy político de la detención de un obrero en aquel abril del 39 y de las andanzas de su hijo tras el padre. Da una idea falsa y rojiza de nuestro lado.

"La risa": Unos prisioneros rojos caen en manos de los nacionales. La risa la tiene uno de ellos ante las cosas que ve. El capitán nacional y un falangista tienen una orgía con ribetes formales religiosos con una prostituta. Por supuesto hay malos tratos y fusilamiento. Paraíso comunista $37,75,144 . "$

A la vista de la severidad de los informes y del peso del discurso político en estos relatos, contrario a la hegemonía de la ideología dominante, la Superioridad solicita de los servicios policiales información detallada sobre las actividades y movimientos del autor. El comunicado, que forma parte del expediente, y que los servicios policiales remiten con prontitud, recoge su profesión, obras publicadas aprobadas y denegadas-, camarillas de las que forma parte, actividades relacionadas con la lucha subversiva. Precisan que:

En febrero de 1962 se le concedió el premio "Antonio Machado", a la mejor novela en castellano, dotado con 10.000 nuevos francos, por su novela Año tras año. Este premio se otorga en Perpignan por la editorial Ruedo Ibérico, de significación política marxista conocida.

En mayo de 1962 intervino en un ciclo de reuniones-coloquio sobre el cine y la novela, organizado por un grupo al que se le conoce con la denominación de "Joven Cultura Española".

Por el mes de marzo, según emisiones de "Radio España Independiente" (que radia desde Praga), figura entre los firmantes españoles y portugueses de una carta que se dice dirigida desde Florencia al Presidente Kennedy, protestando contra la ingerencia norteamericana en Cuba. No consta fehacientemente que firmara tal escrito.

Figura entre las personas de diversa significación y relieve que firmaron unos escritos elevados a los Sres. Ministros de Información y Educación Nacional en noviembre de 1960, pidiendo una mejor organización y dulcificación de la censura gubernativa ${ }^{15}$.

\footnotetext{
${ }^{15}$ José Luis Cano se refiere a estos escritos en los que se exponía el disgusto de los escritores españoles por el mantenimiento y rigidez de la censura y menciona a algunos de los intelectuales que los suscribieron entre los que aparece la firma de López Salinas. Cano da noticia asimismo de la reunión frustrada que mantuvieron con el director general de Cine y Teatro -García Escudero-, en representación del ministro de Información -Fraga Iribarne-, el 27 de julio de 1962, a la que acudió
} 
Se ha podido comprobar que es también una de las personas que firmaron un escrito de adhesión a la conferencia pro-amnistía de presos y exiliados políticos españoles, celebrada en París en marzo de 1961, de evidente inspiración comunista ${ }^{16}$.

El manuscrito está integrado por 16 relatos de desigual extensión ${ }^{17}$. El primero, "Crónica de un viaje" es el más largo y, como en todos los demás, hay una clara postura política de izquierdas, el mismo compromiso político que ya perfilara en La mina y esgrimiera en Año tras año. En ellos se repiten los mismos temas y con los mismos planteamientos: el sometimiento de los vencidos en la guerra civil, la miseria, la cárcel, la prepotencia y crueldad de los nacionales y su alianza con la Iglesia Católica, la defensa de la justicia y la libertad para todos. Los dieciséis relatos que forman el volumen son todos ellos testimonio del oscurantismo que a los

López Salinas junto a otros escritores y en la que expusieron quejas contra el sistema de censura, aludieron a casos concretos y pidieron, sigue diciendo Cano, además de la necesaria liberalización de la censura, que se acabe con el anonimato de los censores todopoderosos (1986: 141, 157).

${ }^{16}$ Los escritores sociales aunque reconocen el débil impacto que su literatura tiene sobre la evolución socio política, afirman que su voz llegó a los organismos de decisión. Dice López Salinas a Núñez al respecto: "Es bastante posible que, en tanto que escritores, no hayamos influido mucho nunca; pero como intelectuales -al menos desde que yo nací a la vida literaria- la voz del escritor ha estado presente en problemas fundamentales, que no son del caso relatar, de la vida del país" (Núñez, 1966: $4)$.

${ }_{17}$ Unos versos de Carlos Álvarez le sirven de introducción. Pertenecen al "Pequeño poema a los emigrantes" del libro Escrito en las paredes y son los siguientes: "sudor que se derrama en otros vasos/ torrente que alimenta otras cosechas/ canciones que completan los paisajes/ de un suelo diferente. España mía/ España nuestra os llama y os espera/ y os busca y os precisa, compañeros/ desarraigados frutos de mi tierra." No parece una estrategia acertada iniciar el libro con las palabras de este poeta andaluz comprometido en la lucha política contra el fascismo, que por problemas de censura tuvo que publicar sus primeras obras fuera de España -en Dinamarca, Suecia, Francia, Italiay que su primer libro no pudo aparecer en su país hasta 1969. Los títulos de esos relatos son: "Crónica de un viaje", "Costa del Sol", "Aprendiz de panadero", "Ni casta", "Aquel abril", "La viuda", "La abuela tenía hambre", "Muchacho", "La comida de los perros", "La hoja en blanco", “Debajo del cerezo", “El calor humano", “La risa”, “La caída”, “Luna roja”, “La cosecha”. 
hombres y mujeres de España les tocó vivir durante las primeras décadas de autarquía $18 .^{18}$.

El tan traído y llevado "Aquel abril" se localiza en Madrid al término de la guerra civil. Detienen a un republicano, lo llevan a la cárcel de las Salesas y su hijo, que ronda la zona en busca de noticias, ve cómo le sacan y le llevan a fusilar, como a otros muchos. La miseria, la emigración forzosa, el hambre, el odio de la posguerra, la humillación que soportan los derrotados de la guerra civil, pero también la firme y orgullosa defensa de sus ideas y la esperanza en un mundo más justo, son también motivos relevantes en estos relatos.

En el expediente hay una carta de Seix Barral en la que tras conocer el veredicto de censura, solicita la revisión y alega en defensa del relato "Aquel Abril", que mereció el premio Acento del S.E.U., y fue publicado íntegramente. La revisión se efectúa pero no se altera el veredicto ${ }^{19}$. A Crónica de un viaje y otros relatos no se le denegó expresamente el permiso de edición pero fue tan sustancialmente mutilado que autor y editor debieron tomar la decisión de no publicarlo en aquellas condiciones y ha permanecido inédito desde entonces ${ }^{20}$.

Muchos de los escritores de este periodo, adscritos o no a la corriente del realismo social imperante, se sintieron tentados por los libros de viajes. Este subgénero dio frutos de diferentes especies y grados de madurez, desde las

\footnotetext{
${ }^{18}$ En la encuesta que Olmos García realiza a distintos escritores, a la pregunta sobre las condiciones indispensables para que el escritor pueda contribuir al cambio social en su país, López Salinas contesta que, la imprescindible es la democratización de sus instituciones de forma que el creador no se plantee "un apriorístico imposibilismo y una autocensura" (1963: 223).

${ }^{19}$ En la revisión se dice que es falsa la afirmación de Seix Barral, pues "Aquel abril" figura en la antología con tachaduras en las páginas 82 a 90. (Véase nota 11).

${ }^{20}$ En 1997 se publicó un volumen colectivo de cuentos titulado Relatos subterráneos (Madrid, editorial Popular/Unesco, 1997) que anunciaba uno de López Salinas. Sin embargo, sólo se trata de una publicidad engañosa porque lo que el volumen recoge no son más que unas páginas de La mina.
} 
modalidades de tratamiento estético considerable hasta el documento periodístico o sociológico.

Aunque todos los críticos señalan la herencia de una cierta tradición de la literatura española por los libros de viajes, que data del medioevo, florecen en todas las épocas y suscitan interés particular en el 98. El antecedente inmediato, como tantas veces se ha apuntado, es el Viaje a La Alcarria, de Cela.

La crítica ha atribuido una serie de rasgos comunes a estas obras cuyo hilo conductor es siempre un recorrido, a pie en muchos casos, por una región determinada, que debe ser enfocado a través de la técnica de la narración objetiva, y que por lo general se acompañaba de información gráfica -mapas del itinerario, fotos, etc.- que permitan al lector seguir el recorrido y sirvan de refuerzo a lo que pretende ser un documento testimonial. Su escenario es, invariablemente, la España rural, esa España que, habiéndose iniciado ya la etapa de los ajustes económicos subsiguientes al Plan de Estabilización de 1959, que sentaron las bases del desarrollismo, se iba a quedar al margen de la recuperación económica e iba a sufrir muy directamente las consecuencias de dicha política ${ }^{21}$.

Otro aspecto distintivo de los libros de viajes es la autoría compartida. Posiblemente este hecho esté relacionado con la necesidad de identificación y pertenencia a una generación comprometida en unos fines concretos, así como con la búsqueda de la veracidad y la imparcialidad, lo que quizá pueda conseguirse mejor aunando dos voces narrativas que neutralizan el carácter de cada una de ellas.

\footnotetext{
${ }^{21}$ Los años de la industrialización y de la aparición de la clase media en las grandes ciudades son precisamente los de la emigración masiva al extranjero y los de la despoblación del campo. La brecha que se abre entonces entre la España rural y la urbana no se cerrará sino muchos años más tarde.
} 
El lenguaje es sencillo, ajustado a la técnica de la instantaneidad coloquial y el diálogo recoge la especificidad de la fonética popular de las regiones que se describen 22 .

El afán por conseguir la verosimilitud descriptiva de una realidad convierte a muchas de estas obras en una fuente inagotable para la reconstrucción histórica de unas formas de vida hoy olvidadas o en trance de desaparición. El primero de los libros de viajes de López Salinas es Caminando por las Hurdes, que escribió con Antonio Ferres.

En agosto de 1957 los dos amigos emprenden viaje a Las Hurdes para cumplir el encargo de la revista Acento cultural, que publicará en números sucesivos desde 1958 a 1961 y con el título de "Estampas de un viaje", los distintos capítulos del que después será Caminando por las Hurdes, considerado por la crítica uno de los mejores y más representativos libros de viajes de la época ${ }^{23}$. La literatura de viajes fue tan abundante en las décadas 50, 60 y 70, que no quedó un rincón en el país sin su libro

\footnotetext{
${ }^{22}$ En mi artículo (2004: 109-122), analizo los antecedentes y características de este subgénero, recojo los libros de viajes más representativos de esa década antes de centrarme en dos obras de Grosso de autoría compartida, Por el río abajo, que escribió con A. López Salinas y A poniente desde el Estrecho, con Manuel Barrios.

${ }^{23}$ Los primeros capítulos salieron en noviembre de 1958. El libro lo publicó en 1960 Seix Barral, en su colección Biblioteca Breve, con ilustración de Luis Buñuel y Oriol Maspons y una tirada de 5000 ejemplares. El expediente -núm. 1873-60- se resolvió con algunas rectificaciones y supresiones insignificantes. El informe, del que ya dio cuenta Abellán (1980: 202), dice: “Impresiones recogidas al paso por Las Hurdes, con bastantes concesiones al tópico hurdiano. Nada fundamental que objetar. Sin embargo, debe suprimirse la palabra subrayada en el folio 96, por equívoca, y la 120, por malsonante, (al igual que todas las que corresponden a la misma expresión)". Las expresiones censuradas son: "los curas no trabajan y comen bien" -p. 24; "puta", "jodío" y "carajo" en páginas diversas, que sustituyeron los autores por las iniciales seguidas de puntos suspensivos. Aunque íntegramente habían aparecido ya en Acento. Esta revista, de corta vida pero importante presencia 1958-1961- patrocinada por el SEU, fue, como bien señala Oscar Barrero (1991: 7-22,), el baluarte de las opiniones socialrealistas y tuvo frecuentes enfrentamientos con la Estafeta Literaria, portavoz de las posturas oficialistas. Caminando por las Hurdes tuvo una $2^{\mathrm{a}}$ edición en 1974 y se ha reeditado recientemente (Madrid, Gadir, 2006).
} 
de viaje. Algunos lugares, como Las Hurdes, fueron de insistente peregrinación y no sólo por los viajeros de la posguerra ${ }^{24}$. Gil Casado (1973: 428-434, 435-443) ha hecho una amplia descripción de los temas y recursos de la obra y a ella remito para evitar repeticiones

El relato se complementa con un mapa del itinerario que siguieron los autores y un conjunto de testimonios gráficos que en parte proceden de fotogramas del célebre reportaje de Buñuel y en parte de fotografías tomadas treinta años después, en 1960, y cuya similitud sorprende al lector actual. La voz narradora cumple con precisión su papel, y bien ella misma, bien a través del diálogo entre los viajeros o entre estos y los jurdanos, va retratando con gran sobriedad aunque no disimula la mirada solidaria y compasiva. Las viviendas, el campo, la alimentación y las condiciones físicas de los habitantes se describen con un lenguaje sencillo y transparente: no se le oculta nada al lector, pero tampoco se abusa ni se cae en la trampa del naturalismo mal entendido. La comarca de Las Hurdes, paradigma de abandono secular, fue objeto de otros acercamientos posteriores ${ }^{25}$. Caminando por las Hurdes obtuvo un gran eco dentro y fuera de España ${ }^{26}$.

Armando López Salinas firma, también con su amigo Ferres, un reportaje titulado "Por campos de Toledo. Un lugar de la Mancha", que les encarga la revista Triunfo. Los viajeros marchan por tierras de la Mancha camino de Valdecañas. A su paso dan fe del duro trabajo del campo, que también realizan los niños, el cultivo de

\footnotetext{
24Modesto Rubén Martínez Reche da testimonio de los libros sobre Las Hurdes cuyos antecedentes se remontan al siglo XVII y constata que a lo largo del siglo XX fue lugar común para escritores, intelectuales y cineastas como tópico de pobreza española y símbolo de la "España negra" (1995: 225253).

${ }^{25}$ En 1968 se publicó Las Hurdes: tierra sin tierra, de Víctor Chamorro y en 1972 Las Hurdes, clamor de piedras de José Antonio Pérez Mateos. Ambos libros fueron analizados por Santos Sanz Villanueva (1980: 786-790, como representativos de autores menos conocidos y no necesariamente miembros de la corriente socialrealista.

${ }^{26}$ No solo fue traducido a diversos idiomas sino que fue también publicado en Les Temps Modernes, la revista de gran prestigio que dirigía Jean Paul Sartre.
} 
la vid, el paro encubierto, la tierra poco repartida, la mitad de sus habitantes viviendo en cuevas; el ir y venir de las gentes de un pueblo anodino, aburrido, falto de vida. El reportaje se complementa con unas fotografías del pueblo y sus gentes. Pasó desapercibido para la censura27.

Entre 1960 y 1961 López Salinas escribe junto a Alfonso Grosso Por el río abajo, su segundo libro de viajes, que tiene una larga historia de reveses. En la nota introductoria escrita cinco años después para anunciar la primera edición, fechada en París en enero de 1966, los autores ponen en conocimiento del lector que "en el mes de agosto de 1960 realizaron un viaje a pie por tierras de la Baja Andalucía, exactamente a lo largo del delta del Guadalquivir". Añaden que

razones obvias de explicar, directamente relacionada con la censura previa, impidieron entonces que las impresiones escritas durante su viaje pudieran ser publicadas en España porque en España sólo pudo publicarse quince años después de haber sido escrito28.

Aunque Por el río abajo sigue el modelo de Caminando por las Hurdes, presenta algunas diferencias. La miseria legendaria del viaje por las Hurdes se recoge en un documento de considerable expresión dramática, mientras que el caso de la baja Andalucía es muy diferente: la tierra aquí es rica pero se concentra en pocas manos y el pueblo soporta la miseria. La situación de latifundio hace que los viajeros contrapongan continuamente al jornalero y al terrateniente. Hay muchos más detalles costumbristas, la descripción paisajística es riquísima y los narradores, parcamente, sin largas diatribas y en tono sereno que solo excepcionalmente deja

\footnotetext{
27 Aparece en dos números de la revista: Triunfo, 23, XVII (10 de noviembre de 1962): 68 y 76, XVIII (16 de noviembre de 1963): 8. Estas colaboraciones tenían una difusión extraordinaria porque la revista anunciaba en su portada a bombo y platillo que sobrepasaba una tirada de 50.000 ejemplares.

${ }^{28}$ La segunda edición de este libro, con prólogo de Antonio Ferres, se llevó a cabo en España después de la transición política (Bilbao, Albia, 1977). En el prólogo que Ferres escribe para la ocasión, dice que se trata de un testimonio vivo, trepidante, tembloroso, comprometido hasta el latir de la sangre, escrito bajo los cánones del realismo documentalista en una atmósfera de miedo, de falsos ídolos, bajo una dictadura terrorista, cuando un hombre cualquiera había de huir, temer y disimular su rabia.
} 
paso al desahogo personal, denuncian injusticias o las ponen en boca de los segadores, pescadores o jornaleros.

El libro fue presentado en febrero de 1962 en el Ministerio de Información y Turismo para solicitar la aprobación de edición. Pasó por censores distintos que señalaron múltiples tachaduras y todos coincidieron en que se le debía denegar la publicación, como así fue. Fue publicado en Francia, perdido, por tanto, y desconocido por los lectores españoles ${ }^{29}$.

Pero López Salinas vuelve a insistir con un tercer libro de viajes, que pasó totalmente desapercibido para la crítica, esta vez con Javier Alfaya, Viaje al país gallego (López Salinas, A. y Alfaya, J.: 1967). Está dividido en cuatro capítulos, que llevan el nombre de cada una de las provincias gallegas y presenta las mismas características técnicas que los anteriores. Un narrador objetivo en tercera persona se detiene en la historia de pueblos y ciudades, describe el campo, los pueblos de pescadores, las fondas, el trasiego de las tabernas, las costumbres, las fiestas, pero no pasa por alto el atraso y el analfabetismo de sus gentes, sus supersticiones, la emigración forzosa, la necesidad de una profunda reforma agraria, el nacionalismo, la laxa moralidad para la época. Casi todos -hombres y mujeres- se expresan en gallego y el lenguaje espontáneo, vivo, coloquial inunda todo el relato.

Viaje al país gallego tendrá serios problemas con la censura y pasará por distintos lectores ${ }^{30}$. El primero escribe:

\footnotetext{
${ }^{29}$ Este libro ha sido objeto de mi artículo (2004: 109-122). En él estudio, a la luz del expediente de censura y otros documentos, todas las pruebas a las que el libro fue sometido y las peripecias que autores y editor tuvieron que soportar. Muestro, así mismo, muchos de los párrafos mutilados.

30 En marzo de 1966 se crea una nueva Ley de Prensa con el pretexto de desarrollar al máximo la libertad de la persona aunque teniendo siempre en cuenta el bien común y la paz social. Pero sus principios se apoyan en los mismos que se apoyara la Ley de 1938. El cambio fundamental reside en que se da inicialmente más libertad pero se sanciona con mayor rigidez a posteriori. La única diferencia real está en que ya no es obligatoria la consulta previa a la edición aunque el editor debe presentar varios ejemplares antes de ponerlos a la venta. No es de extrañar que en la práctica no hubiera muchos editores que se arriesgaran a publicar un libro sin tener antes la tarjeta de
} 
Al limitarse los autores a reflejar ambientes de pobreza y dialogar siempre con gente iletrada, dibujan una crítica contra los anteriores y actual régimen en materia de política económica y agraria. Ya que ninguno de ellos ha llegado a resolver los grandes problemas gallegos.

Obra llena de intención política, encubierta apenas bajo la pintoresca descripción de unos tipos y ambientes literariamente bien logrados.

Deben ser suprimidos los párrafos indicados en las páginas 1, 2, 16, 17, 52, 83, 88, 94, 95, 101, $105,106,122,117,121,125,155,177,179$ y 182.

Son muchas las páginas que presentan tachaduras en el manuscrito pero el segundo censor aún pondrá impedimentos en algunas más.

En rigor, solamente conversan con campesinos y gentes iletradas y solamente reflejan o quieren reflejar lo que estos sienten y dicen con su agudeza proverbial. Apenas si hurgan en otras capas sociales. No parece interesarles lo que estas pudieran expresar en un elemental empeño de probar que en Galicia hay algo más que estrechez campesina y economía rudimentaria... Hay algunos deslices marginales hacia equívocos de sabor separatista y obrerista o proletario. Por ello aconsejamos la supresión de lo subrayado en los folios 1, 2, 97, $103,108,120,124,125$.

El tercer informe pone el acento en los mismos temas y añade algún otro echando así más leña al fuego con estas palabras:

Acusan la intención de escribir una obra de serio carácter informativo, pero en realidad poco más hacen que repetir tópicos pintorescos y delatar una tendencia ligeramente izquierdista, anticlerical y nacionalista en sus reflexiones y diálogos.

El suscrito ha encontrado justificadas las acotaciones hechas por algún otro lector para supresión y añade algunas pocas más por cuenta propia ${ }^{31}$.

autorización. La ley del 66 no supuso un paso adelante en el camino de la libertad de expresión, sino un cambio de estrategia del Gobierno que necesitaba mejorar sus relaciones con los países democráticos. La editorial Península de Barcelona solicita, pues, el permiso en octubre de 1966, cuando acaba de hacerse efectiva la nueva Ley, y se le asigna el número de expediente 6379-66; recorrerá un difícil camino.

31 Tras la lectura de estos tres informes la Superioridad resuelve que deben llevarse a cabo las supresiones marcadas en las páginas 1, 2, 88, 101, 106, 121, 122, 125, 177, 179, 183. 
Las supresiones que deben llevar a cabo afectan considerablemente al libro, pero los autores deciden continuar, presentar nuevos textos con el objetivo de que el libro vea la luz aunque sea mutilado ${ }^{32}$. Saben que no pueden eludir el castigo pero lucharán para que no se vea gravemente alterado. A continuación voy a copiar en dos columnas algunos de los párrafos mutilados y las correcciones que los autores introducen, para que el lector pueda valorar la trascendencia del dictamen.

\footnotetext{
32 Esta era una práctica frecuente. Los autores, por lo general, no asumían el castigo, no aceptaban las supresiones sin antes intentar llegar a un acuerdo con el órgano represor. Proponían, así, textos modificados, de forma que el daño no fuera irreparable, y si también estos eran rechazados, en su lugar solía aparecer una larga línea de puntos suspensivos. Los puntos suspensivos eran síntoma, para los lectores avisados, de que había habido una supresión por autocensura o por imposición de la censura. Su uso fue práctica común; unas veces por obligación, otras por elección de los autores o por consejo de los editores, salvaban así su responsabilidad de creadores.
} 


\section{Textos originales}

Cierto es que Galicia se afirma como nacionalidad tal como Cataluña $\Theta$ Euskadi- dentro de un estado cuya trayectoria histórica no tiene parangón. (Manuscrito: 1)

Los autores de Viaje al país gallego emprenden su marcha en el año en que se eumplen los cinco siglos de la Hermandad Gallega, la gran insurrección campesina que hizo conmover a la triple alianza feudal de nobles castellanos, portugueses y gallegos. Ya no quedan fortalezas que derribar, pero la causa profunda que movió a aquellos hombres a sacudirse el yugo secular todavía permanece. A los viajeres les parece que la obra que los "irmandiños" iniciaron aún tiene que ser cumplida.(Manuscrito: 2)

\section{Textos propuestos}

Cierto es que Galicia se afirma como pueblo, al igual que vascos y catalanes, dentro de un estado cuya trayectoria histórica no tiene parangón (López Salinas, A. y Alfaya, J., 1967: 7)33.

Ahora, cuando los viajeros emprenden su caminar, es 1965. Tiempo en que se cumplen los cinco siglos de la Segunda Hermandad Gallega, insurrección popular en la que los labradores y colonos, organizados en ejército, destruyeron fortalezas y casas solariegas, y tomaron, en algún caso, conmoviendo al poder feudal, posesión de la tierra por ellos cultivada. Verdad es que, como señalan los historiadores de la época, los nobles, ya fueran gallegos, portugueses o castellanos, ayudados en su empresa por el Arzobispo de Santiago y otros eclesiásticos más o menos innominados, se tomaron bien pronto el desquite frente a los confederados. Zurita, en sus "Anales de Aragón". Escribe que con la intervención de los Reyes Católicos en aquel tiempo se comenzó a domar aquella tierra de Galicia.

Las fortalezas, aún pueden verse las ruinas, quedaron derruidas para siempre. Galicia ya no es del conde de Lemos y

\footnotetext{
${ }^{33} \mathrm{El}$ afán de independencia de los gallegos en distintos órdenes, la devoción nacionalista y el rechazo por la administración del Estado, que el libro refleja, pronto fue atajado por los censores; pocas bromas se podían hacer entonces en ese sentido.
} 
media docena de nobles más, pero la causa profunda que moviera a aquellos hombres a sacudirse el yugo feudal todavía permanece. A los viajeros les parece que si bien el paso de los siglos se ha cumplido, aventando un buen puñado de problemas, aún, en lo esencial, tiene que ser concluida la obra que en su día iniciaron los "irmandiños", y que esta tarea, no cabe olvidarlo, sólo podrá ser rematada, sin jamás traicionarla, por obreros, marineros y campesinos (López

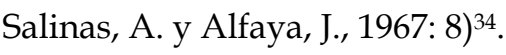

Los pazos son antiguas casas señoriales (...). En tiempos tuvieron los pazos una función bien precisa en la sociedad gallega: eran el refugio de una aristocracia campesina que poco a poco fue desapareciendo ante el empuje del poder central. Luego, lo fue de una burguesía que no supo crear una nacionalidad, que se convirtió, traicionando a su pueblo, en simple delegada del gobierno castellano.

(Manuscrito: 106)

Luego lo fue de una burguesía que, viviendo de espaldas a su pueblo, no interpretando sus características peculiares, por los treinta dineros en pago a su celestinaje, se convirtió, cuando más, en representante de intereses no gallegos (López Salinas, A. y Alfaya, J., 1967: 134) $)^{35}$.

\footnotetext{
${ }^{34}$ El texto propuesto triplica la extensión del mutilado y añade nuevos y peligrosos datos, como la alianza secular entre la Iglesia católica y los poderosos y la intervención de los Reyes Católicos en la aniquilación de cualquier rebelión de origen popular. Pero por si esto fuera poco, los autores echan más leña al fuego al proclamar que aquella revolución, abortada entonces, está aún por producirse. No se explica cómo este texto pudo imprimirse.

35 El nuevo texto no restringe la extensión ni aligera el contenido, antes al contrario, incide con más fuerza si cabe, en la función que se atribuye a los pazos de encubridores y mediadores de acciones reprobables de intereses cercanos al gobierno franquista, centralista.
} 
En otros casos los autores deciden cumplir el castigo impuesto y suprimir los fragmentos mutilados sin proponer nuevos textos. En su lugar aparecen los puntos suspensivos. Veamos algunos ejemplos:

Santiago, en cierto sentido, es una ciudad valle-inclanesca. Sus primeros libros están atravesados por el recuerdo de esta ciudad, de sus calles... Y aquí en 1936, murió Valle.

- Ya sabéis lo que pasó después. Bicen que unos bestias quisieron desenterrar el cadáver y fusilarlo. No les llegó con fusilar a los vives ${ }^{36}$ -

Cuando llegan a Finisterre, los viajeros recuerdan estos versos:

Santo Cristo de Fisterre

Cristo da barba dourada,

axudádame a pasare

a negra noite de Espanha ${ }^{37}$.

Uno de los últimos pueblos que visitan en su caminar es Pasantes y así lo describen:

Pasantes no tiene iglesia (...) Los Pasantes es un lugar triste, un lugar que es como un mal sueño. Los viajeres se dicen que a sitios tales nunca llegará el progreso de forma evolutiva, que haría falta algo capaz de conmover los cimientos de este pueblo, de esta provincia, de España entera-(manuscrito: 182$)^{38}$.

\footnotetext{
${ }^{36}$ La imagen extravagante, rodeada de anécdotas pintorescas que hicieron de Valle un personaje más literario que real, no esconde ni anula su postura de opositor y crítico de una sociedad arcaica y tradicional que muchas veces encarna en Galicia ni su actividad pública, manifestándose o participando en asociaciones o solidarizándose con movimientos de oposición. Su muerte en la ciudad de Santiago de Compostela el 5 de enero, poco después de su vuelta de Roma donde había sido nombrado por el Gobierno de la República Director de la Escuela de Bellas Artes, no era un recuerdo que la censura quisiera resucitar.

37 Así aparecen (manuscrito: 125). Sólo quedaron en pie los dos primeros versos. Los otros dos se convirtieron en una larga línea de puntos suspensivos.

${ }^{38}$ Las líneas mutiladas no se imprimieron. El inmovilismo de la región, del Estado, la situación política, social, económica e ideológica de estancamiento, debía ser silenciada desde todos los medios.
} 
En el expediente hay una Nota al ejemplar presentado a depósito en la que se dice que se han suprimido o modificado la mayor parte de las tachaduras, pero añade:

sin embargo, hacemos constar a la Superioridad que (...) en la página 8 ha sido insertado un nuevo párrafo que no aparecía, en un sentido muy marcado de separatismo... En la pág. 122 se hace una clara y terminante alusión al comunismo, y se dice que cerrar el puño es el saludo usual y corriente entre los marineros gallegos ${ }^{39}$.

A pesar de esta nota, se permite la "normal difusión de la publicación".

López Salinas es también autor de una obra de teatro infantil titulada El pincel mágico. Se trata de una historia de comportamientos maniqueos, de ricos malos y pobres buenos, una historia en la que, al contrario de lo que ocurre en sus relatos y novelas, triunfan el bien y la justicia ${ }^{40}$. En el informe, el censor explica con todo lujo de detalles el contenido de la obra. Dice así:

Obra de teatro infantil adaptada de una leyenda china.

Me-Liang es un niño pobre que recoge leña del bosque. Nadie quiere pagarle su trabajo e incluso el maestro le niega la instrucción en la escuela. Un día, se le aparece un mago y le entrega un pincel que le convertirá en realidad todo cuanto pinte. Así sucede en efecto, causando la envidia de todos y principalmente la de Mú, poderoso propietario, quien obliga a Me-Liang a entregarle el mágico pincel; pero dicho instrumento convierte en piedras el dinero que el ambicioso Mú dibuja. Al final devuelve al niño su pincel y cuando éste traza por mandato de aquel, un paisaje de mar, las olas se llevan al tirano.

Me-Liang en lo sucesivo sólo pintará para los pobres.

Puede editarse.

\footnotetext{
${ }^{39}$ Los autores, jugándose el libro, que podía haber sido, como tantos otros, secuestrado, desafían a los censores y, devueltas las galeradas y antes de la impresión, incluyen algunas frases o párrafos. Los de la página 8 ya han sido comentados en la nota 48. Además, la alusión al uso habitual de los gallegos del saludo comunista, puño en alto, nunca habría visto la luz si antes hubiera aparecido en galeradas. Es un caso de flagrante desobediencia; el primero que encuentro en mis años de investigación en el AGA.

${ }^{40}$ La solicitud la presenta Germán Sánchez Ruipérez en representación de la editorial Anaya. Se le asigna el expediente número 1052-64 e incluye un manuscrito.
} 
Toda la trayectoria literaria de López Salinas tiene un denominador común, un realismo crítico que le llevará a se enfrentarse con la censura de forma sistemática. Afrontó durante más de dos décadas, literaria y vitalmente, la dura y opresiva mentalidad del franquismo porque su creación era su forma de entender la realidad, de reflexionar sobre los problemas sociopolíticos de la España de su tiempo. Nuestro autor, dice Mangini (1987: 121), y yo comparto su opinión, es el ejemplo más extremo del marxismo abnegado que se entregó a la literatura por tener fe en su función política. Nunca se desvió de su camino de activista. Por este motivo su creación fue silenciada y casi anulada por la censura franquista. Abandonaría la literatura en 1967 y desde la transición a la democracia se dedicará plenamente a la política.

\section{BIBLIOGRAFÍA}

Abellán, M. L. (1980): Censura y creación literaria en España (1939-1976), Barcelona, Península.

Barral, C. (1978): Los años sin excusa, Barcelona, Tusquets.

Barrero, O. (1991): “El reducto de la estética socialrealista: Acento cultural (19581961)", España contemporánea, IV: 7-22.

Boulanger, M. (1962): “A. López Salinas: La mine”, La Nouvelle Revue Française, 116: 334-335.

Cano, J. L. (1986): Los cuadernos de Velintonia, Barcelona, Seix Barral.

Conte, R. (1960): “La mina de A. López Salinas”, Acento cultural, 7: 34-35.

Doménech, R. (1962): “Sobre unas limitaciones expresivas”, Ínsula, 192: 4.

Ferreras, J. I. (1970): Tendencias de la novela española actual 1931-1969, París, Ediciones Hispanoamericanas.

Ferres, A. (2002): Memorias de un hombre perdido, Madrid, Debate.

Fontenla, S. (1960): “Los nuevos novelistas", Cuadernos de Arte y Pensamiento, 4: 129132.

Gil Casado, P. (1973): La novela social española, Barcelona, Seix Barral.

Gil Novales, A. (1961): “La mina de A. López Salinas”, Cuadernos Hispanoamericanos, 133: $140-142$. 
Grosso, A. y López Salinas, A. (1966): Por el río abajo, Paris, Editions de la Librairie du Globe.

Gubern, R. (1981): La censura. Función política y ordenamiento jurídico bajo el franquismo (1939-1975), Barcelona, Península.

López Salinas, A. (1960): La mina, Barcelona, Destino.

López Salinas, A. (1962): Año tras año, "Premio Antonio Machado", París, Ruedo Ibérico.

López Salinas, A. (1962): “Una historia familiar”, Triunfo, 23: 68-70.

López Salinas, A. (1965): El pincel mágico, Salamanca, Anaya.

López Salinas, A. y Ferres, A. (1960): Caminando por las Hurdes, Barcelona, Seix Barral. López Salinas, A. y Alfaya, J. (1967): Viaje al país gallego, Barcelona, Península.

Mangini, S. (1987): Rojos y rebeldes. La cultura de la disidencia durante el franquismo, Barcelona, Anthropos.

Martínez Reche, M. R. (1995): “Libros de viaje: Tres miradas a las Hurdes”, en J. Ramos Ortega et alii (eds.) (1995) 225-253: Literatura española alrededor de 1950: Panorama de una diversidad, Cádiz, Servicio de Publicaciones de la Universidad. Montejo Gurruchaga, L. (2004): “Alfonso Grosso y la literatura de viajes de los años sesenta: dos miradas a las tierras andaluzas", Philologia Hispalensis, XVIII: 109122.

Montejo Gurruchaga, L. (2006): “Alfonso Grosso y el realismo social. Dos novelas de los años sesenta", Archivum, LVI: 205-231.

Montejo Gurruchaga, L. (2006): "La censura de género en la narrativa de autora durante las dos primeras décadas del franquismo", Voz y Letra, XVII/2: 103118.

Montejo Gurruchaga, L. (2009): “Escritoras españolas de posguerra. Reflexión y denuncia de roles de género", en Pilar Nieva-de la Paz (coord. y edición) (2009) 187-204: Roles de género y cambio social en la Literatura española del siglo XX, Amsterdam/ New York, Rodopi (Foro Hispánico 34).

Neuschäfer, H. (1994): Adiós a la España eterna. La dialéctica de la censura. Novela, teatro y cine bajo el franquismo, Barcelona, Anthropos.

Núñez, A. (1966): “Encuentro con A. López Salinas”, Ínsula, 230: 4. 
Olmos García, F. (1963): “La novela y los novelistas españoles de hoy”, Cuadernos Americanos, XXII: 211-237.

Sanz Villanueva, S. (1980): Historia de la novela social española (1942-1975), Madrid, Alhambra.

Sinova, J. (1989): La censura de la prensa durante el franquismo, Madrid, Espasa Calpe.

Vázquez Zamora, R. (1960): “Las novelas del premio”, Destino, 1170: 24-26.

Sobejano, G. (1975): Novela española de nuestro tiempo. En busca del pueblo perdido, Madrid, Prensa Española. 